\section{Flood defence for financial hubs}

Hurricane Sandy is likely to have been a heart-stopping event for officials in many coastal cities around the world - particularly in Shanghai, given its low elevation and complementary status to New York as the financial hub of China.

Shanghai's flood barrier was built more than 20 years ago to protect the old city in Puxi along the Huangpu River waterfront. It could be inadequate against a sea-level rise resulting from this century's predicted $2^{\circ} \mathrm{C}$ temperature increase due to climate change.

The new financial district across the river in Pudong was constructed at a higher elevation, but its defences could be breached if temperature rises are larger, such as the potential $6^{\circ} \mathrm{C}$ increase identified as an upper threshold by the PricewaterhouseCoopers Low Carbon Economy Index (see go.nature.com/jvv381).

Officials in other low-lying coastal cities that are principal economic centres, including Tokyo, Hong Kong, Mumbai and Sydney, need to work out how best to enhance their own protection.

James H. Vance Taylor, Texas, USA.

jhv@compuserve.com

\section{Tightening up on tree carbon estimates}

During a recent fieldwork campaign with a logging operation in the southwestern Amazon, we weighed a single shihuahuaco tree (Dipteryx micrantha) at 76.1 tonnes dry mass, making it the most massive tropical tree ever recorded. Yet its diameter (158 centimetres) and its height (44 metres) were unexceptional. Marked variations in the biomass and species identity of large trees have significant implications for carbon accounting and the future of tropical forests.

Forest biomass is usually quantified using equations that include parameters such as trunk diameter, height and wood density. However, for this tree, commonly used indirect methods yielded a wide range of estimates, from $17 \%$ to $98 \%$ of its true mass. Although the biomass of large trees is notoriously difficult to predict, this sixfold range demonstrates the scale of the problem.

Carbon stocks can vary greatly among different species. Dipteryx trees have dense wood, slow growth and long lives (up to 1,000 years; J. Q. Chambers et al. Nature 391, 135-136; 1998). This is not true of other tree species in the same area. For example, a 115-cm diameter Cavanillesia umbellata weighed a mere 2.3 tonnes, which is 12 times lighter than a second $D$. micrantha of comparable size.

This enormous difference in the biomass of two trees of similar dimensions demonstrates the urgent need to improve our understanding of large-tree allometry.

Rosa C. Goodman, Oliver L. Phillips, Timothy R. Baker School of Geography, University of Leeds, UK.

rosa.goodman@gmail.com

\section{Global science can bolster diplomacy}

The globalization of scientific research (see, for example, Nature 490, 325-329; 2012)

has helped to strengthen diplomatic relations between countries around the world, complementing foreign-policy agendas (Nature 470, 425-427; 2011). This underscores the far-reaching impact of governments' investment in science.

As microbiologist Louis Pasteur (1822-95) aptly remarked, "Science knows no country, because knowledge belongs to humanity, and is the torch which illuminates the world."

Lindsay Chura University of Cambridge, UK.

lrc36@cam.ac.uk

\section{Medicalization of sleep may be needed}

As noted by Meredith Wadman in her review of Matthew Wolf-Meyer's book on US sleep medicine, The Slumbering Masses (Nature 490, 173-174; 2012), the sweeping generalization that sleep is unnecessarily "medicalized" ignores the drastic consequences of insufficient sleep. Sleepmedicine physicians, like all doctors, have an ethical responsibility to diagnose patients who have a suspected health disorder and to provide them with the most effective treatment.

Chronic sleep deprivation increases the risk of illness and accidents and curtails productivity. Insomnia, the most common complaint, is also associated with a host of morbidities, including psychiatric disorders such as severe depression and the associated risk of suicide. Left untreated, insomnia will seriously damage an individual's health and quality of life.

Sleep medications approved by the US Food and Drug Administration can safely provide relief from insomnia when used properly under the supervision of a physician. Clinical guidelines from my institution, the American Academy of Sleep Medicine, recommend that sedativehypnotic drugs should be supplemented with behavioural and cognitive therapies, that the lowest effective dose should be prescribed and that medication should be tapered when conditions allow.

Sam Fleishman American Academy of Sleep Medicine, Darien, Illinois, USA. sfleishman@aasmnet.org

\section{Real skin shedding meets mythology}

The African spiny mouse represents the first instance of skin shedding in a mammal in which molecular science and the imagination of our ancestors find a common home (A. W. Seifert et al. Nature 489, 561-565; 2012).

Stories abound of mammals that can shed and regrow their skins. A letter from the British scholar C. J. Grece to Charles Darwin in 1866 discusses the tale of a large black pig, reported in London's Morning Star newspaper (see go.nature. com/szb5df). Grece wrote that the pig "cast its entire skin from the snout to the tail, together with subcutaneous fat of from one to three inches in thickness, leaving a second skin now exposed to the external air.... The former skin was black and bristly, the new one was, at first, entirely flesh coloured but is changing to black by degrees.... [The pig] has now naught the matter with it."

In mythology, a creature known as a selkie, for example, was supposed to shed its skin as it morphed from seal to human. In his Just So Stories, Rudyard Kipling in 1902 described a rhinoceros that "took off his skin and carried it over his shoulder as he came down to the beach to bathe". His neighbour, the Parsee, rubbed that skin with "tickly cake-crumbs and some burned currants" so that, unlike the insouciant pig described to Darwin, the rhinoceros was left "from that day to this" with "a very bad temper".

Andrew C. Walls University of Massachusetts Medical School, Worcester, Massachusetts, USA. andrew.walls@umassmed.edu Vanessa E. Johnson Vanderbilt University School of Medicine, Nashville, Tennessee, USA. Scott A. Norton Children's National Medical Center, Washington DC, USA. 